Dossier: La escritura en los desplazamientos: viajes, expediciones y naufragios

\title{
La escritura en los desplazamientos: viajes, expediciones y naufragios
}

\section{Presentación}

La escritura de los desplazamientos ofrece una cartografía y una geografía que complementa un viaje y ofrece una imagen diferente del espacio y de lo que lo circunda. A su vez la escritura de un desplazamiento espacial implica una doble operación metafórica, en primer lugar la del viaje mismo y el tránsito entre un espacio y otro y, en segundo término, la del lenguaje, es decir la de la elaboración simbólica en la construcción de significados a partir de significantes y es, en la escritura misma, donde esa imagen queda plasmada.

Los artículos que conforman este Dossier, además de trabajar sobre la doble metáfora de la escritura de los desplazamientos, examinan de qué manera los escritos sobre viajes, expediciones y naufragios ofrecen un universo de información sobre distintos campos del saber y del conocimiento. Se trata de un conjunto de trabajos diversos que se abordan temáticas, textos, perspectivas, períodos y objetos de estudio variados que van más allá de los textos canónicos de la literatura de viajes. En estos encuentros y desencuentros con la palabra desplazada y viajera, vista desde un caleidoscopio transdisciplinario, se agrupa una selección de artículos que fueron compartidos en un encuentro internacional celebrado en octubre del año 2019 en el marco de la Cátedra Humboldt, actividad de la Vicerrectoría de Investigación de la Universidad de Costa Rica. En el Dossier colaboran intelectuales de instituciones académicas de Alemania como la Universidad de Bielefeld, de los Estados Unidos como la University of Massachusetts-Darmouth, la Universtity of Oklahoma y la University of Toledo, de México como la Universidad Veracruzana y, por supuesto, de la Universidad de Costa Rica.

\section{(c) (i) (2)}

La Revista Estudios es editada por la Universidad de Costa Rica y se distribuye bajo una Licencia Creative Commons Atribución-NoComercial-CompartirIgual 3.0 Costa Rica. Para más información envíe un mensaje a 
Dossier: La escritura en los desplazamientos: viajes, expediciones y naufragios

Este esfuerzo está dedicado a la memoria del colega mexicano Yordi Enrique Gutiérrez Barreto, para quien fue la última oportunidad de compartir en un encuentro académico debido a su infortunada y temprana partida, no obstante sus investigaciones dejan un valioso legado que, a manera homenaje, iluminan este conjunto de artículos pues según sus palabras alrededor de las composiciones líricas sobre los naufragios anotaba:

"Temas y motivos son el lenguaje de nuestro contacto cognoscitivo con el mundo y es gracias a ellos que la literatura es una de las representaciones más exhaustivas de la existencia. El naufragio literario representa la postura que adopta el poeta respecto a su mundo y, en mucho, a sus expectativas vitales. En consecuencia, su creación resulta una postura filosófica ante la vida, una verdadera poética." 16

En este sentido, los trabajos reunidos en este Dossier presentan diversas y variadas posturas filosóficas, verdaderas poéticas, que dan cuenta de posturas ante el mundo y expectativas vitales y representaciones de la existencia en el devenir de la doble metáfora de la escritura en los desplazamientos.

Dr. Leonardo Sancho Dobles

Catedrático Humboldt 2019 Universidad de Costa Rica, Costa Rica leonardo.sancho.dobles@gmail.com https://orcid.org/0000-0001-8707-3488

${ }^{1}$ Gutiérrez Barreto, Yordi Esteban, La poética del naufragio: evolución de un motivo en la lírica del Siglo de Oro, tesis para obtener el grado de Licenciado en Lengua y Literatura Hispánicas, México, UNAM, 2019, p. 16.

\section{(c) (i) (2)}

La Revista Estudios es editada por la Universidad de Costa Rica y se distribuye bajo una Licencia Creative Commons Atribución-NoComercial-CompartirIgual 3.0 Costa Rica. Para más información envíe un mensaje a 